The Geneva Papers on Risk and Insurance, 21 (No. 80, July 1996), 393-400

\title{
The Insurance of Natural Hazards: Proposals to an Appropriate Risk Partnership Between Insurers, Reinsurers, the Government and the Policyholders
}

\author{
by Burkhardt Meyer*
}

\begin{abstract}
The coverage of natural hazards through the private insurance industry is possible if it is based on a sensible risk partnership. A partnership between the insurance and reinsurance industry, the policyholders and the government for establishing the legal framework or, if necessary, as reinsurer of last resort. Solutions involving compulsory insurance and flat premiums or other interventionist measures are comparatively disadvantageous. They often assume the form of taxes that are levied among the population as a whole but are redistributed among only a minority. They offer no incentive to avoid endangered regions or to take steps to prevent or reduce loss. This leads to a steady increase in loss potential resulting from the subsidizing of poor risks. And this is undesirable at least in the long term since it results, as only too often in the case of subsidies of all kinds, in the faulty allocation of economic resources. In many cases the capacity provided by the insurance industry is sufficient to cover the risk of natural catastrophes.
\end{abstract}

\section{Natural Catastrophes}

The economical and insured losses caused by natural catastrophes - whether these constitute earthquake, storms or floods - are constantly on the increase (illustration). The reasons for this are many and varied. The increasing world population is one contributing factor, as are the movement of people into regions that are particularly threatened by natural hazards as well as the trend towards industrialization, which has the effect of concentrating ever higher values into ever smaller areas. Signs that the atmosphere is gra-

* Member of the Executive Management, Munich Reinsurance Company. 


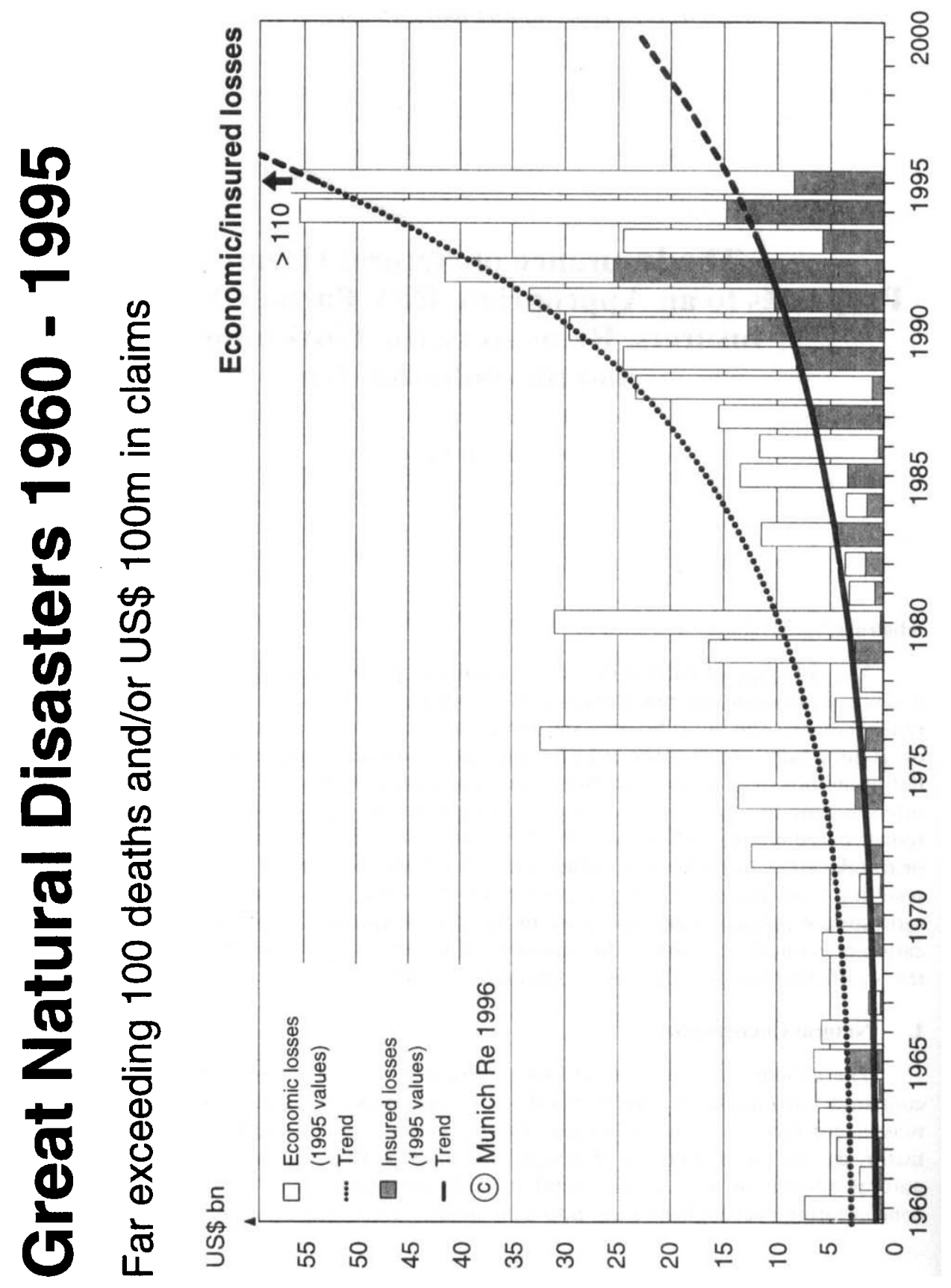


dually becoming warmer are also increasing. This may result in more frequent and more severe storms and floods.

With every spectacular natural catastrophe that occurs, the public becomes involved in a broad discussion of the possible causes, prevention and consequences of such events. This discussion also turns on the role of the insurance industry. The insurers are sometimes accused of compensating the victims of natural catastrophes inadequately, if at all, for the losses they have suffered. This gives rise very quickly to calls for intervention by the state which is required to regulate matters in such a way as to prevent the supposed abuses.

Are such calls for government intervention in this connection justified? Or, in other words: are natural catastrophes insurable and, if so, what are the respective roles of the government, the policyholders and the insurance industry?

\section{Insurability of natural catastrophes}

In the professional literature, three main criteria are usually named as a precondition for the insurability of a risk: its fortuitousness, the determination of the expected financial loss and the amount of the loss in question.

The fortuitousness of a loss implies that uncertainty must exist as to its causation and/or time of occurrence and/or extent. This precondition is generally fulfilled in the case of natural catastrophes, since only one of these criteria needs to be met. In the case of earthquake and windstorm it is always fulfilled. In the case of flood, on the other hand, insurability can be limited to some extent if the probability of a loss occurrence is extremely high. This aspect will be discussed in more detail in the following.

The potential financial loss resulting from a natural catastrophe has to be determinable. Otherwise it is impossible to calculate the risk adequate premium for the risk assumption by the insurer. In the case of natural events, the calculation is in principle possible. The joint efforts of geologists, meteorologists, hydrologists and actuaries have resulted during the last few years in major advances in this respect. Most progress has probably been achieved in the area of earthquake research. The scientific basis with regard to windstorm has become increasingly reliable and substantial efforts are being made currently in connection with the risk of flood. A particular problem in the case of windstorm and flood is the so-called risk of change, which can arise as a result of global warming. This risk of change is, however, not something specific to natural hazards insurance, and it is as difficult to quantify here as it is in other classes of insurance. It is therefore presumably safe to assume that the risk of change alone is not a factor that makes natural catastrophes uninsurable. In assessing the risk it is thus necessary not only to consider the current situation but also to anticipate possible future trends in this respect.

The amount of an expected loss is of importance in that it must not exceed the sum that would ruin an individual insurer or lead to the collapse of the insurance industry as a whole. A promise to pay compensation that could not be realized in the loss event would be worthless. The major proportion of the natural catastrophes can be covered by the insurance industry. Some scenarios, however, are conceivable in which the insurance industry's capital resources might be exceeded worldwide. How this ruin probability can be limited 
and the insurability of natural catastrophes expanded as a result will be investigated further in the following.

Insurance of natural catastrophes is from a technical point of view possible. To be successful a risk partnership is necessary, embracing the government, the insurance industry and the policyholders. The risks must be carried on a global basis to provide the appropriate coverage.

The solutions presented in the following will be largely market-driven ones. A number of cases will be examined in addition, however, that involve elements of government intervention.

\section{Risk partnership}

\subsection{The role of the government}

Under a liberal economic system, it is basically not the task of the state to assume risk or to influence the way in which risk is transferred. This must be left to the private elements of the economy interacting with each other within a free market environment, at least up to the point where objectives as opposed to politically motivated limits are reached. This means that the government is responsible in the first place for establishing the necessary legal framework. As far as natural hazards' insurance is concerned, this implies among other things that the state must allow the insurance industry some means of making financial provision for its obligations by allowing the setting up of tax-free reserves. This is necessary in order to ensure the spread of liabilities over time in view of the long return periods of the losses. In the case of earthquakes, for example, the return periods are 100 years or more, and in the case of storm decades. The surpluses gained in claim-free years cannot be declared as profits but must be set aside as reserves for the exceptional loss that is bound to occur at some time.

It should also be possible, to retain these reserves, at least to some extent, in the form of foreign investments. In the event of a major catastrophe it may, for instance, be difficult to realize domestic securities at a reasonable price in a sellers' market. Company shares especially can lose dramatically in value if the companies concerned are themselves affected by the same catastrophe or if the disturbance of the infrastructure resulting from the catastrophe precludes normal production.

Owing to the magnitude of catastrophic loss events and their relatively long return periods, it is often not possible to absorb the resulting strains within the insurance industry of a single economy. The government must therefore be responsible for ensuring the free movement of both services and capital. For only then can the local direct insurers increase their own capacity by purchasing protection from the internationally operating reinsurance companies. They in turn can ensure the spread of risks on a global basis.

The government is also in charge of supervising insurance activities. In this connection it is responsible for overseeing the solvency of the insurance companies, so as to ensure that they are in a position to meet their liabilities. The solvability of an insurance company, in turn, is considerably influenced by the possibilities available for building tax- 
exempt reserves and by the extent of engaging in the free movement of services and capital, so that the reinsurance market can commit itself appropriately.

In the context of the risk partnership between government, the insurance industry and the policyholders, the state also has certain tasks to fulfil in connection with the prevention and minimization of loss. It is the duty of governments, for instance, to establish and enforce building regulations to ensure that structures in earthquake-endangered regions will be able to withstand certain shocks or that buildings particularly exposed to storms will stand up without damage to a certain degree of wind pressure. Another duty is that of erecting dams for the prevention of flood. The responsibility of the state can and should go as far as allowing it to forbid certain forms of land usage in areas that are particularly exposed - for example in the immediate vicinity of known earthquake epicentres or in river valleys that are subject to annual flooding. Measures to prevent additional global warming also fall within the area of government responsibility. These include measures for the realization of Agenda 21, resolved at the World Climate Summit.

On the other hand, in a number of countries regulations have been established that were either imposed directly by the government, or considerably influenced by the state. In Switzerland, for example, there is a traditional natural hazards pool, which was given a federal law basis in 1993. In almost all the Swiss cantons, natural hazards coverage forms an obligatory part of every fire insurance policy. The pool itself, however, obtains its backing from reinsurers at market prices. A similar arrangement applies in Norway, where natural hazards are included compulsorily under fire policies in return for a flat premium. The so-called Naturscadepool then also obtains reinsurance coverage on the open market. There are obligatory covers also in France (Catastrophe naturelle) and in Spain (Consorcio de Compensación de Seguros). Also in Japan an earthquake pool has been established. It insures premises inly and distributes the liability among the insurance industry and the government. In the USA the Federal Flood Insurance, based on the Housing and Urban Development Act of 1968, grants coverage against the peril of flood in extremely exposed areas.

\subsection{The role of the insurance industry}

Within the risk partnership, the role of the insurance industry represented by both direct insurers and reinsurers, is to carry the risks concerned. To enable this, certain technical preconditions have to be met.

\subsubsection{Technical preconditions}

It has already been said that the expected financial loss resulting from a natural catastrophe must be calculable to a sufficiently accurate degree. This makes it possible to determine the correct premium. In a market-based system it is not sufficient to calculate an average premium for all risks regardless of their individual exposure. This is unjustifiable from both the macro-economic point of view and from that of individual business management.

It is economically unjustifiable because, in the case of an average premium, the price of the insurance protection would not be linked to the cost of its production. This would necessarily lead to a faulty allocation of resources. In addition, it is the price that a policy- 
holder has to pay that determines whether it is worth to take measures for loss prevention, or whether he will decide to establish himself in a highly exposed area in the first place. In an area that is prone to earthquake, for example, a reinforced concrete building on a solid rock foundation will represent a more favourable risk than a brick building erected on a land-fill.

It is equally unjustifiable from the business management point of view because it would inevitably result in adverse selection for the insurer. Risks with a below-average loss expectation would then have to subsidize the risks with a higher-than-average loss expectation which would result in a loss of custom to insurers offering more favourable terms.

All the arguments against premium differentiation are based mainly on either social grounds or reasons of solidarity and are less influenced by financial or economic considerations. If a government were to compel its insurance industry to offer level premium rates, it would merely force it to act as its assistant in the exercise of its sovereign duties. The premiums would then partially assume something of the nature of a tax, which the insurers redistribute to the disaster victims. Such a procedure would result, from the moment when the funds available for compensation were no longer adequate, in the need for a series of interventionist measures, such as compulsory insurance and government guarantees. In addition, such a system would be virtually designed to relieve the state of its duties in respect of loss prevention, damage control and other measures for the reduction of loss. It can be reasonably assumed that as a result the loss potential would increase .

The charging of risk adequate premiums provides an answer also to the question on the possibility of insuring risks that are highly likely to be realized. These may include, for example, the risks of monsoon floods in India or Bangladesh, which tend to occur regularly each year, or of the almost inevitable overflowing of European rivers during the spring snow-melt. If insurers demand a premium in such cases that is really commensurate with the risk, then the whole question of insurance becomes irrelevant for the client concerned. In such cases the insurance transaction would degenerate into a mere exchange of funds, carrying the additional burden of taxes and costs.

In addition to the need to calculate the appropriate price, another technical precondition for the provision of insurance against natural catastrophes is the need for transparency as regards the total value of the objects to be insured. This is essential because a natural event can cause damage to a large number of insured items: in other words, the items concerned cannot be treated independently of each other. Since such accumulations of individual losses have to be treated as a single insurance event, the insurer has to be aware of their potential extent.

The instrument for dealing with this problem is accumulation control. For this purpose for many countries in the world that are particularly susceptible to natural catastrophes, accumulation assessment zones have been agreed upon. This is done under the auspices of CRESTA, a global working group of insurers, reinsurers and other interested parties that is concerned, among other things, with uniform zoning. The purpose of this standardization process is to assess the extent of liabilities in the various areas and to make the relevant data available to insurers. This information forms the basis for PML calculations, which finally determine the amount of capacity that can be made available. 
It is primarily at the direct insurance level that the technical preconditions for the insurance of natural hazards are established. It is the task of the direct insurers above all to calculate the risk adequate premiums, to ensure that those premiums are collected and to conduct accumulation controls. Internationally operating reinsurers can provide assistance on the basis of their experience of similar problems in other parts of the world.

\subsubsection{Risk assumption}

As regards the assumption of the risks concerned, direct insurers are limited in their possibilities, at least if they operate only within a limited geographical area. Owing to the problem of accumulation, they have little or no opportunity to spread their risks. The many individual risks they assume accumulate very quickly to form one major risk that will soon overstep the bounds of their capacity. The probability of financial ruin then becomes intolerably great. As a result, they have to turn to the reinsurance market for protection.

As regards the accumulation aspects, reinsurers initially face the same problem as direct insurers. They do, however, have a decisive advantage over the direct insurers: if they operate internationally, which is generally the case, they can spread their risk globally. And they can do this all the more efficiently, the more they are engaged in independently exposed regions of the world. They are therefore eager to do business in as many different countries as possible, thereby extending their capacity in this way.

Here too, it becomes clear how necessary it is to charge risk adequate premiums and to secure the free movement of capital. International reinsurers will scarcely be willing to participate in risks at inadequate premiums, even if the national direct insurers are obliged to do so in accordance with local regulations. In addition, the reinsurers will need to have free access to the necessary financial resources, because they have to balance their portfolios internationally and to make the requisite funds available where they are needed. Shortages of coverage arising as a result of such circumstances are not genuine capacity bottlenecks. Rather, they are the result of a non-market orientated behaviour.

Even if all the requisite economic background conditions are present, scenarios are still conceivable in which the probability of ruin for the insurance industry as a whole has become so great that real capacity shortages can occur. An example is the earthquake exposure of greater Tokyo, where the overall economic loss could amount to $\$ 3,300,000$ million, or of San Francisco, where the loss could run to $\$ 220,000$ million. In such extreme situations it is necessary to have recourse to the state. For not only can the government demand or itself implement stricter standards of loss prevention or reduction, it can also act itself as risk carrier or money-lender. It can, for example, step in as reinsurer once the capacity of the private insurance and reinsurance industry has been exhausted. In this way, it acts for the insurance industry as the «reinsurer of last resort», backed not only by a limited amount of risk capital but by an entire national economy. In addition, the state can provide intermediate financing for very large losses, to allow the private insurance industry to spread its own loss burden over a longer period of time. In how far the government is nowadays financially in a position to engage itself in such a scheme, will not be discussed further. 
But even the policyholders, as the third partner in the risk-bearing community, can contribute substantially to ensuring that capacity shortages arise, if at all, only at a much later stage. By doing this they also prevent themselves from suffering losses.

\subsection{The role of the policyholder}

Policyholders, as the parties seeking protection from the consequences of loss, should make sure that they adhere in the first place to the official building regulations and should also take measures of their own for the prevention and minimization of loss. They will be all the more inclined to do this, the more risk adequate the premium is calculated. The implementation of such loss reduction measures must be reflected in the price of the insurance to the extent that they reduce the burden on the insurance industry.

Policyholders should also be required to participate in any loss that does occur. A loss deductible has a double effect.

On the one hand, the number of claims to be processed in the event of a catastrophe will thereby be greatly decreased. On the other hand, the overall loss strain will also be considerably reduced, even in the case of relatively low deductible amounts. Besides this a co-insurance by the policyholders is possible. It is an additional incentive to implement loss prevention and reduction measures. Analyses of recent loss events have yielded some interesting results in this respect. In the case of the European windstorm Daria of 1990, for example, a loss deductible of DM 1,000 per risk would have reduced the overall loss from damage to private residential buildings in Germany by $50 \%$. The number of claims would have been reduced even by $65 \%$. And although this would not have the effect of increasing overall capacity, it would contribute towards the ability of the private economy to deal with catastrophic losses. 